Indian Journal of Science and Technology

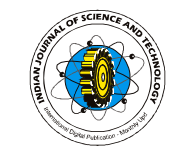

\title{
Structure of human errors in tasks of operators working in the control room of an oil refinery unit
}

\author{
Niloufar Shah Gholi-Nejad ${ }^{1}$, Mohammad Javad Jafari ${ }^{2 *}$, Mehran Ghalehnoi ${ }^{3}$, Yadollah Mehrabi ${ }^{4}$, Mohsen ghadiri ${ }^{5}$ and \\ Mahmood Nikbakht ${ }^{6}$ \\ ${ }^{1}$ Department of Occupational Health Engineering, School of public Health, International branch of Shahid Beheshti \\ University of Medical Sciences and Health Services \\ ${ }^{2}$ Occupational Health Engineering Department, Faculty of Health, Shahid Beheshti University of Medical Sciences, \\ Tehran, Iran \\ ${ }^{3}$ Department of Occupational Health, Faculty Member, Qazvin University of medical science, Qazvin, Iran \\ ${ }^{4}$ Department of Epidemiology, School of Public Health, Shahid Beheshti University of Medical Sciences, Tehran, Iran \\ ${ }^{5}$ Sharif university of technology, Strategic management PHD \\ ${ }^{6}$ Department of Environmental Science, Science and Research Branch, Islamic Azad University, Tehran, Iran \\ Jafari1952@yahoo.com*; Jafari1952@yahoo.com
}

\begin{abstract}
In the present research, human errors existed in tasks of operators working in two control rooms (Northern and Southern control rooms) in the Tehran oil refinery are identified and evaluated. Then, corrective strategies and actions are advised to decrease errors. At first, using hierarchical task analysis (HTA) method, four positions including shift controller, head operators, control room's operators, and outside operators are analyzed. Afterwards, human errors in the considered positions are identified and assessed using technique for retrospective and predictive analysis of cognitive errors (TRACEr). Results present 670 internal errors and 738 external errors in the Northern sector while 661 internal errors and 744 external errors in the Southern sector. In two sectors, this number of errors was identified for 27 major tasks and 108 minor tasks. Action errors are the most repeated errors among the internal errors while violation errors are the least. In addition, most of external errors are related to communication errors while the least errors are related to time and sequence errors. According to results of applying psychological error mechanism (PEM) in the considered positions, people's distraction is the main factor causing errors. Performance shaping factors (PFS) identifies lack of training as the major factor for errors. Using TRACEr, all external and internal errors, psychological error mechanism, and primary factors of errors in the control room can be detected.
\end{abstract}

Keywords: Operator; Human error; TRACEr; HTA, Tehran Oil Refinery.

Introduction

Studies indicate that human errors are the direct and indirect factors of $90 \%$ of all industrial accidents (Reason, 1990). Accident related to human errors can incur much financial losses and fatality. According to current statistics, in the late 30 years, 75 out of 157 accidents in the oil and gas offshore facilities have led to fire, financial losses, and casualties equal to 3 billion dollars and 187 dead. $34 \%$ of these accidents were due to human errors and $38 \%$ was due to inappropriate maintenance of equipment (ICSO, 2004a). The largest recorded disaster originated from human errors is a broad fire in Britain offshore oil rig platform in the Northern Sea, Piper Alpha, occurred in 6 July 1988, ICSO (2004b). The fire which was ignited by exit of gas condensates from one of the pipes of condensers of gas unit led to a chain of explosions and fire which finally resulted in destruction of whole platform and facilities ICSO (2004b). Some terrible accidents such as explosion in Flixborough (1974), airplane crash in Tenerife (1977), accident in Three Mile Island's nuclear power plant (1979), Bhopal's factories in India (1984), explosion of space shuttle Challenger (1986), Chernobyl's nuclear explosion (1986), and troubles in work of Mir space station (1998) could show the important role of human errors in happening of industrial disasters.

Research article

CIndian Society for Education and Environment (iSee)

"Human errors in industrial operation"

http://www.indjst.org
Basically, human beings play critical roles in oil and gas processes with high risk of fire and explosion (Zarei, 2009). In addition, as mentioned, human errors contribute much in accidents and disasters. Thus, prediction and identification of factors leading to human errors in the oil and gas industry can contribute much in improving the safety of such system and decrease in the industrial hazards. Tehran oil refinery with daily production capacity of 350,000 barrels is one of the largest refineries in Iran. In addition, Tehran oil refinery is one of the oldest facilities with 40 years of existence. This refinery is located in south edge of metropolitan Tehran. So, any disastrous event in this refinery could result in huge financial losses and fatalities. Therefore, studying different aspects of safety in this facility is the main focus of the present research. There are numerous techniques for identification of human errors. One of the major methods is technique for retrospective and predictive analysis of cognitive errors (TRACEr) which was originally developed by British national service of air traffic to classify human errors and identify their causes in the traffic control sector (RSSB, 2005; Shorrock, 2002). TRACEr, mainly based on human factors, analyzes human errors through hierarchical task analysis (HTA) approach and assists analyzer to realize the type and cause of the errors. In this method, external error modes 
(EEM) are determined after applying HTA. Then, error domain and internal error modes (IEM) are determined. This technique uses psychological error mechanism (PEM) in tasks assigned to people and performance shaping factors (PSF). Finally, it presents all Table 1. Frequency of tasks and identified errors stages to identify and recover errors (RSSB, 2005; Shorrock \& Kirwan, 2002). In July 2002, Shorrock and Kirwan applied this technique to detect human errors in air traffic control (Shorrock \& Kirwan, 2002). Le Bot (2004) presented human errors, accidents, and reliability models through the Three Mile Island's accident analyses. Zhang et al. (2004) applied TRACEr to identify errors and cognitive taxonomy of medical errors. Shorrock (2005) concentrated on memory errors in air traffic control while Shorrock (2007) and later focused on perception errors in air traffic control using TRACEr. Some merits of TRACEr are: Simplicity in apply; Less time of identifying errors; Less time of advising corrective actions. In most of previous research, to detect errors using TRACEr, HTA has firstly been applied to identify and analyze tasks. In the current paper, first hierarchical structure of all tasks involved in control room is analyzed and determined. Then, errors are realized through TRACEr.

\section{Methodology}

The present investigation focuses on human errors involved in tasks of operators working in two control rooms of units including Isomax, catalytic conversion, and hydrogen units of the Northern and Southern sectors of Tehran oil refinery. The research includes two major parts. In the first part, using HTA, all tasks of operators working in control room are studies. To do so, shift controller and heads of three units of work shifting (control room's operators, outside operators, and HSE experts) were interviewed to collect required data. then, their responses were compared with the organization's documents including personnel job description, work regulations and instructions, reports of equipment's maintenance, and working conditions reports. Then, major and minor responsibilities of each position were determined and verified by all interviewees. In HTA, all duties of a person are divided into minor duties through a hierarchical process. To decompose a duty, a final goal is

\begin{tabular}{|l|l|l|l|l|l|}
\hline Major & Minor & \multicolumn{2}{|l|}{ Internal error } & \multicolumn{2}{l|}{ External error } \\
\cline { 3 - 6 } task & task & Northern & Southern & Northern & Southern \\
\hline 10 & 34 & 226 & 220 & 264 & 262 \\
\hline 5 & 31 & 139 & 143 & 145 & 149 \\
\hline 5 & 16 & 86 & 86 & 100 & 103 \\
\hline 7 & 27 & 211 & 212 & 237 & 230 \\
\hline 27 & 108 & 662 & 661 & 746 & 744 \\
\hline
\end{tabular}
main criterion for determining the hierarchy of analysis is the analyzer's personal judgment which depends on most detailed activities which are probable to happen (Stanton \& Salmon, 2004). In the second part of this research, using TRACEr human errors in duties are detected and studied. This part of research was done according to Fig. 1 and also through observing working conditions, examining results of working accidents, and TRACEr (Shorrock \& Kirwan, 2002; RSSB, 2005; Ghalenovi, 2006). The worksheet used for TRACEr in this study is attached in the Appendix. In this part of research, external and internal errors of each position were identified. Then, causes of each error were analyzed. In addition, psychological mechanism and causes of internal errors were determined. Afterwards, performance factors effecting on occurrence of error were determined to predict errors and identify and recover errors (Shorrock \& Kirwan, 2002; RSSB, 2005).

Results

Results of the current research are presented in two parts corresponding to two parts of research:

\section{Results of hierarchical task analysis}

Using HTA, totally 54 major tasks and 216 minor tasks were identified in two control rooms in the Northern and Southern sectors. Table 1 shows all identified major and minor tasks.

\section{Results of TRACEr}

Results of identifying external and internal errors: Totally, 1323 internal errors and 1490 external errors were identified. Table 1 indicates the number of each type of error for positions and units. Based on results, the maximum frequency of external and internal errors were related to position of shift controller while the minimum frequency of external and internal errors were related to position of control room's operators in the Northern and Southern sectors.

Frequency of external and internal error modes: Internal error includes perception, memory, decision, and action

defined and all minors are determined according to the set goal. Duties are described based on operations and work design (sequence and how operations are done). Afterwards, each operation is divided into subsets. How deep this hierarchical decomposition process goes on depends on the analyzer's opinion. The

\begin{tabular}{|c|c|c|c|c|c|c|c|c|c|c|}
\hline \multirow[t]{2}{*}{ Position } & \multicolumn{2}{|c|}{$\begin{array}{l}\text { Perceptio } \\
\mathrm{n}\end{array}$} & \multicolumn{2}{|c|}{ Memory } & \multicolumn{2}{|c|}{ Decision } & \multicolumn{2}{|c|}{ Action } & \multicolumn{2}{|c|}{ Violation } \\
\hline & $\begin{array}{l}Z \\
\text { 을 } \\
\frac{1}{D} \\
\frac{\mathbb{D}}{3}\end{array}$ & $\begin{array}{l}\mathscr{\infty} \\
\stackrel{5}{\leftrightarrows} \\
\frac{\mathbb{\sigma}}{3}\end{array}$ & $\begin{array}{l}\text { zo } \\
\frac{1}{\frac{1}{7}} \\
\frac{\mathbb{1}}{3}\end{array}$ & 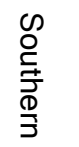 & $\begin{array}{l}z \\
\frac{Z}{3} \\
\frac{1}{\bar{d}} \\
\frac{0}{3}\end{array}$ & 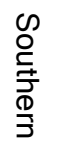 & $\begin{array}{l}z \\
\frac{z}{\frac{1}{7}} \\
\frac{\mathbb{D}}{3}\end{array}$ & 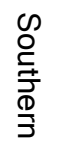 & $\begin{array}{l}\frac{z}{\frac{2}{7}} \\
\frac{\mathrm{D}}{\frac{1}{3}}\end{array}$ & 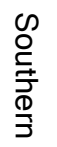 \\
\hline Shift controller & 39 & 42 & 53 & 51 & 45 & 42 & 61 & 60 & 28 & 25 \\
\hline Head operator & 25 & 24 & 34 & 34 & 42 & 42 & 36 & 39 & 2 & 4 \\
\hline Control room's operator & 26 & 23 & 20 & 19 & 18 & 20 & 20 & 21 & 2 & 3 \\
\hline Outside operator & 46 & 44 & 56 & 54 & 43 & 46 & 48 & 50 & 18 & 18 \\
\hline Total & 136 & 133 & 163 & 158 & 148 & 150 & 165 & 170 & 50 & 50 \\
\hline
\end{tabular}


Table 3. Frequency of external errors based on positions and type of error

\begin{tabular}{|l|l|l|l|l|l|l|}
\hline \multirow{2}{*}{ Position } & \multicolumn{2}{|c|}{$\begin{array}{c}\text { Selection and } \\
\text { quality error }\end{array}$} & \multicolumn{2}{|c|}{$\begin{array}{c}\text { Timing and } \\
\text { sequence error }\end{array}$} & \multicolumn{2}{|c|}{$\begin{array}{c}\text { Communication } \\
\text { error }\end{array}$} \\
\cline { 2 - 7 } & Northern & Southern & Northern & Southern & Northern & Southern \\
\hline $\begin{array}{l}\text { Shift } \\
\text { controller }\end{array}$ & 78 & 79 & 63 & 63 & 123 & 120 \\
\hline $\begin{array}{l}\text { Head } \\
\text { operator }\end{array}$ & 23 & 25 & 24 & 23 & 98 & 101 \\
\hline $\begin{array}{l}\text { Control } \\
\text { room's } \\
\text { operator }\end{array}$ & 26 & 25 & 30 & 27 & 44 & 51 \\
\hline $\begin{array}{l}\text { Outside } \\
\text { operator }\end{array}$ & 73 & 70 & 68 & 65 & 96 & 95 \\
\hline Total & 200 & 199 & 185 & 178 & 361 & 367 \\
\hline
\end{tabular}

and violation (RSSB, 2005). Effect of external errors in the studies tasks are presented in Table 2. According to results, in position of shift controller, action error (with 61 and 60 repetitions in the Northern and Southern sectors, respectively) is of the most frequency while violation error (with 28 and 25 repetitions in the Northern and Southern sectors, respectively) is of the least frequency among detected internal errors. In position of head operator, decision error (with 42 repetitions in both Northern and Southern sectors) has the maximum frequency while violation error (with 2 and 4 repetitions in the Northern and Southern sectors, respectively) is of the minimum frequency among internal errors. Perception error (with 26 and 23 repetitions in the Northern and Southern sectors, respectively) and violation error (with 2 and 3 repetitions in the Northern and Southern sectors, respectively) are respectively of the most and least frequencies for the position of control room' operator. In position of outside operator, memory error (with 56 and 54 repetitions in the Northern and Southern sectors, respectively) and violation error (with 18 repetitions in both Northern and Southern sectors) are respectively of the maximum and minimum frequencies.

External error modes are formed by timing and sequence, selection and quality, and communication errors. In the present study, the number of each of these errors in different tasks is determined and shown in Table 3. Results stress that communication error is of the most repeated (maximum frequency). Timing and sequence error in Northern and Southern sectors (63 repetitions), has the minimum frequency for the position of shift controller. In the position of head operator in the Northern sector, selection and quality error is of the least frequency while timing and sequence error has the minimum frequency ( 23 repetitions) for position of head operator in the Southern sector. In position of operator of control room, selection and quality error is of the minimum frequency (25 and 26 repetitions for Southern and Northern sectors, respectively). In addition, for the position of outside operator, timing and sequence error (with 65 and 68 repetitions in the Southern and Northern sectors, respectively) is of the least frequency.

Frequency of mechanisms of external and internal error: All internal error modes including perception, decision,
Vol. 5 No. 2 (Feb 2012)

ISSN: 0974- 6846

action and violation and also external errors including selection and quality, timing and sequence, and communication error are formed from subsets and mechanisms that are presented in tables related to TRACEr in the major report.

Results of identifying psychological error mechanism: In this paper, 18 different factors (mechanisms) for errors by operators of control rooms were detected. These factors include 1-confusion, 2memory capacity overload, 3-distraction, 4misperception of recorded information, 5overload, 6- memory failure, 7-forgetting stored information, 8-work experience, 9-occupational stress, 10-misunderstanding and lack of knowledge to describe details to the next work shifting person, 11forgetting actions and instructions, 12- timing, 13- lack of knowledge in emergency situations, 14- misperception of visual and audio information, 15- miscommunication, 16ignoring current affairs, 17- lack of interest in work, and 18- lack of suitable management abilities to control emergencies. Fig. 2 and 3 show the distribution of frequencies of these mechanisms in the studied tasks (in both Northern and Southern sectors). Numbers in the horizontal axis of each figure indicate the number of mechanisms.

Results of determining performance factors: Regarding the obtained results, lack of training is the primary

Fig. 1. Steps of applying TRACEr

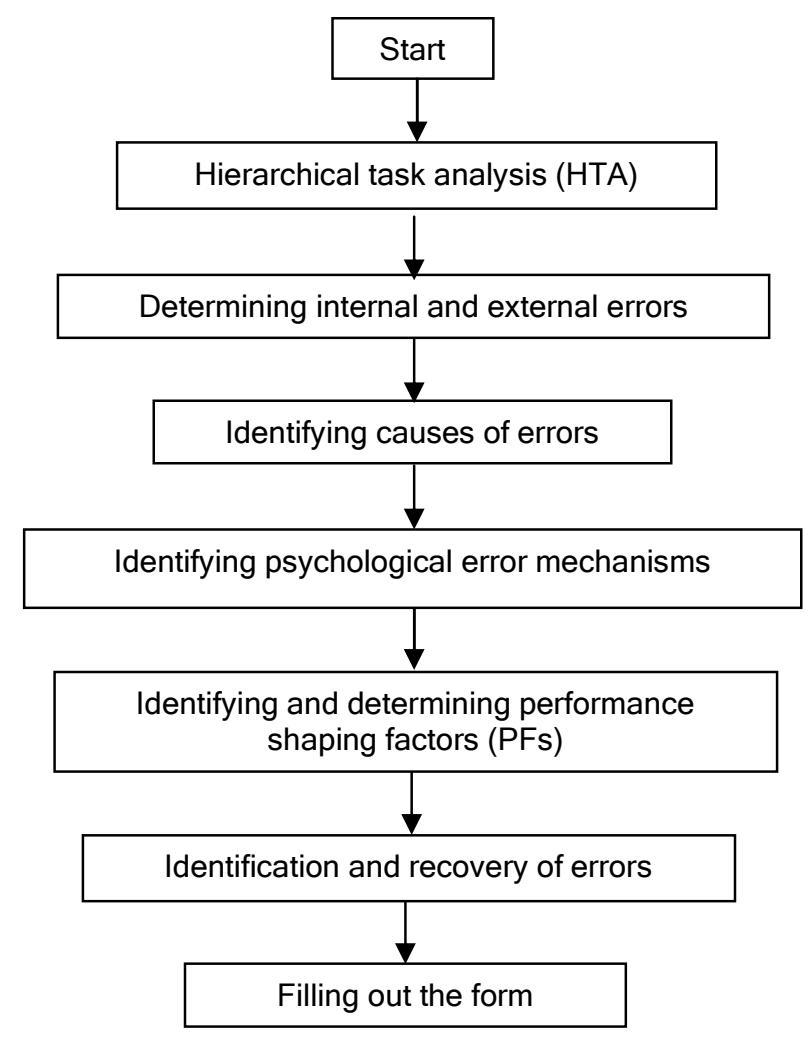

N.S.Gholi-Nejad et al. Indian J.Sci.Technol. 
Fig. 2. Distribution of psychological error mechanisms for studied positions in the Northern sector

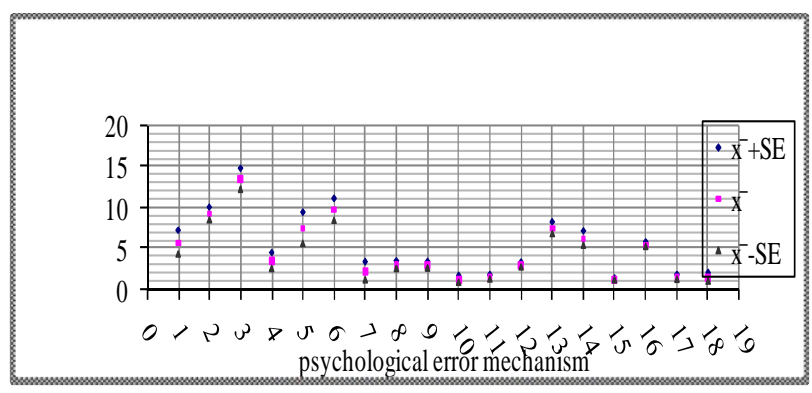

Fig. 3. Distribution of psychological error mechanisms for studied positions in the southern sector

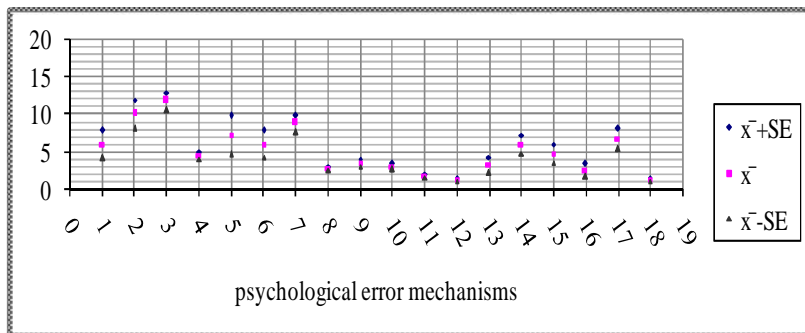

performance factor effective on all tasks of control room (Northern and Southern sectors). In addition, the least factor in the position of shift controller in the Northern sector is the unfamiliarity with emergency situations and lack of concentration on the work. Also, in the Southern sector, lack of experience and existence of stress in the working environment and inability in time management form the least percentage with frequency 2.04. In the position of head operators in the Northern sector, the least frequency belongs to lack of study the working reports with frequency $1.2 \%$. In the Southern sector, lack of focus on work, lack of study the working reports and time pressure have the least frequency $2.4 \%$. In the position of control room's operator, factors such as inaccessibility to instructions, unfamiliarity with emergency situations, stress, lack of study the working reports and lack of concentration of the work are of the least frequency with $1.6 \%$. In addition, in the Southern sector, factors including stress, lack of study the working reports, forgetting actions and instructions, and lack of experience are of the least frequency $1.6 \%$. In the position of outside operators, factors such as lack of study the working reports and stress present in the working conditions are of the least frequency $0.97 \%$.

Results on possibility of error detection and recovery: Basically, the goals of supervision are as follows: a) To examine and control the working conditions and job duties of operators. b) To identify probable deviations from the working procedures and correct the possible deviations.

Supervision is carried out in the Tehran oil refinery in different levels of positions. Potential errors of head operators are identified and recorded by shift controller's supervision. On the other hand, potential errors of outside

Research article

CIndian Society for Education and Environment (iSee) and control room operators are detected and recovered through supervision done by the head operators.

\section{Analysis of results}

Jahangiri, (2005) using HTA method identified 10 critical duties of operators working in the control, room in the Isomax unit of petrochemical industry. In another similar study, Zarea (1996) identified six major duties for operators working in the control room of a cement furnace. In the present study, using HTA method, 27 major duties and 108 minor duties are identified for operators working in the two control rooms in each of Northern and Southern sectors. This number of duties is much more than the number of duties identified in Jahangiri (2005) and Zarea (1996). Results show that details of performance and assigned tasks in different industries can be elaborated through HTA method. Professional tasks are decomposed into minor parts according auditor's discretion. Large number of duties identified in each study could represent the more precision of research and more time and facilities spent in the detection process.

Examining distribution of mechanisms of internal error-perception related to visual misidentification indicates that there is no significant difference between mean of this mechanism in the Northern sector (13.5 \pm 2.38$)$ and the Southern sector (13.25 \pm 4.5$)$. Studies show that increase in concentration on the work can decrease this error.

Examining mechanisms of internal error-memory shows that in both Northern and Southern sectors, forgetting actions (working procedure) with mean $16 \pm 3.91$ in the Northern sector and $15.75 \pm 3.5$ in the Southern sector has the maximum value of error. It is advised to decrease forgetting during work, in all positions, by use of checklists. Suing checklist, all operations are done according to instructions and guidelines which avoids forgetting/omitting any task.

Examining the internal error-decision shows that underestimating the situations for making suitable decisions (with mean $11.5 \pm 3.87$ in the Northern sector and $11 \pm 3.16$ in the Southern sector) is the most critical mechanism for this type of error. Underestimation of the situations originates from lack of knowledge on working conditions and appropriate reaction in emergency situations. Hence, holding specialization training courses (instructions and reactions in emergency situations) for all personnel of Northern and Southern sector of the Tehran oil refinery is strongly advised.

After examining internal error-action, undone actions have the maximum mean in the Northern sector $(15.75 \pm 10.68)$ and in the Southern sector (15.25 \pm 10.14$)$. Thus, root causes of errors in information transmission and record and also not doing actions in the right time should be examined to decrease this error throughout operations. Different causes such as personnel fatigue, dissatisfaction from working conditions and lack of 
training on the work procedure would lead to this error which requires psychological-specialization study.

The maximum number of violations in the refinery is related to daily violation error with mean $7.75 \pm 7.22$ in the Northern sector and with mean $7 \pm 6.58$ in the Southern sector. Correcting working instructions, improving mental conditions in the working environment (increase sense of cooperation in working relations), and rigid supervision on operators could lessen these violations.

Examining external errors indicates that the maximum number of errors is related to communication error with mean $90.25 \pm 7.22$ in the Northern sector and $91.75 \pm 29.18$ in the Southern sector. High values of this error show that there are many defects in the communication system of the refinery.

Generally, communication error happens through vague transmission of information to colleagues, vague and imperfect record of information in reports of unit, defect in transmission of information from operators and wrong transmission of recorded information. Head operators of units are informed through reports of outside and control room's operators. Then, head operators inform Shift controller about operational and system's details. Presence of defect in transmission of information could lead to delay in correcting the operations and complexity in making decision.

Among external errors-selection and quality, forgetting performing an action with mean $10.75 \pm 6.60$ in the Northern sector and $10.25 \pm 4.92$ in the Southern sector has the highest value. A little gap in the values of mean represents similarity in errors in both Northern and Southern sectors.

Regarding conducted studies on control room positions, action error and memory error have the highest and the second highest values among internal errors in the position of Shift controller, respectively. In the position of head operators, the highest and the second highest values of mean among internal errors are respectively related to decision and action. Most of internal errors in the control room's operators are related to perception error. Memory error is of the most internal error for the position of outside operator while action error places on the second rank for the same position. In each of four positions, the most values of external error are related to the communication error.

In a study conducted using predictive human error analysis (PHEA) method on 10 positions in a refinery unit, 161 human errors were detected. 108 of these errors were performance type, 12 were visual, 24 were recoverable, four were selection, five were sequence, and eight errors were related to information exchange (Jahangiri, 2005). In this research, totally 49 performance errors A3 (forgetting considered action) with frequency $30.43 \%$ was detected which this type of error is similar to internal error-memory (L) in the TRACEr method (Zarea, 1996). In a similar study, 222 errors were detected using SHERPA technique in one of control rooms of

Research article

CIndian Society for Education and Environment (iSee) petrochemical industry which 24 of these errors were related to performance error A8 (forget doing the considered action) which is similar to internal errormemory $(L 1,2)$ in the TRACEr method (Ghasemi, 2009). In the present study, 20,53,34, and 56 memory errors were detected respectively in the positions of Northern control room's operators, Shift controller of Northern sector, head operators of Northern sector, outside operators of Northern sector. There is much similarity in the number of detected errors in the Northern and Southern sectors of the Tehran oil refinery. Large number of memory errors in the three studies could show the importance of this type of error in the considered jobs. In fact, forgetting errors are one of the most common errors.

The results of this study show that numerous psychological mechanisms effect on the considered positions. In this regard, operator's distraction with mean $13.5 \pm 2.51$ has the maximum number while weakness in communication (with mean 1.5 \pm 1.73 ) and inability to describe the job's details to the next Shift controller (with mean $1.5 \pm 0.81$ ) have the minim number of errors in the Northern sector. The maximum number of psychological error mechanisms in the Southern sector is of distraction (with mean 11.75 \pm 2.26 ) while the minimum number is of weakness in time management in emergency situations (with mean $1.5 \pm 0.5$ ).

Regarding the results, the maximum number of performance errors in the position of control room's operator in the Northern and Southern sectors are related to lack of training with mean $22.03 \%$ and $20.34 \%$, respectively. In the position of head operator, the maximum number of performance errors in the Northern and Southern sectors are respectively lack of training (with mean 13.025\%) and lack of training and focus on work (with mean 12.05\%). The maximum number of performance factors in the position of Shift controller (both Northern and Southern sectors) is related to lack of training with mean $17.34 \%$ while the minimum number of performance factors for this position in the Northern sector is related to unfamiliarity with emergency situations and lack of focus on the work with mean $2.04 \%$. In the Southern sector, lack of experience and stress on working conditions and time management are the least percentage $2.04 \%$. In the position of outside operator, lack of training and stress/lack study the working reports are respectively of the most and least percentage with mean $17.47 \%$ and $0.97 \%$.

\section{Conclusion}

According to the results, in the positions of Shift controller, the maximum number of internal error is the non- performed action error in that an operator either has defect in transmission or record of information or does wrong actions. Therefore, workload on operators should be decreased. In the position of head operators, the maximum number of internal error is the decision error. Thus, the head operator should dominate on work 
procedures to make decisive and corrective decisions in case of change in the equipment conditions.

The maximum number of internal error for the control room operator is the perception error because the maximum effort is done to concentrate on parameters and gauges on the control board. Thus, some strategies should be considered to increase focus of the operator. The maximum number of internal errors in the position of outside operators is related to the memory error. In this position, operators usually may forget to open or close discharge valve of water containers. In all four positions, the maximum number of external errors is related to the communication error. Mean values of internal and external error identified in this research (in both Northern and Southern sectors) are almost similar. That all tasks in the two control rooms are the same and the errors in the Northern sector are evaluated, by the auditor, the same as errors in the Southern sector, could justify the similarity of mean values for Northern and Southern sector.

Regarding studies, to prevent and decrease human errors in 108 tasks, the corrective actions proposed are: Examining and optimizing reliability of telecommunication system of unit (wireless and telephone system); Repair and increasing emergency calls inside the acoustic chambers; Changes in alert system of control room (alarms); Holding specialization training courses regarding operators' needs; Holding reviewing courses (reviewing the instructions, procedures, and reaction in the emergency situations); Re-examining all instructions of units to change and update them according to unit's process changes; Providing checklists of installation of equipment such as compressors, furnaces, and reactors to prevent omission and forgetting errors; Changing the supervisory plan of the unit; Increasing supervision on tasks may have potential error; Increasing notice and perception skills of personnel through mental practices; Decreasing personnel's workload and stress by increase in resting and leisure times.

\begin{tabular}{l|l|}
\hline $\begin{array}{l}\text { TRACEr worksheet } \\
\text { Major position: } \\
\text { Major task: }\end{array}$ \\
\hline Minor task & \\
\hline Error domain & \\
\hline External error mode & \\
\hline Internal error mode & \\
\hline $\begin{array}{l}\text { Psychological } \\
\text { mechanism }\end{array}$ & \\
\hline Performance shaping factor & Is the error identified? \\
\hline Error detection steps & How is the error identified? \\
\cline { 2 - 2 } & $\begin{array}{l}\text { What are effective factors for } \\
\text { errors detection? }\end{array}$ \\
\hline Error recovery & $\begin{array}{l}\text { Does the operator recover the } \\
\text { error? }\end{array}$ \\
\hline
\end{tabular}

\section{References}

1. Ghalenovi M (2006) Safety analysis of control room operators human error with HEART technique in a petrochemical plant, A dissertation thesis for the

\section{Vol. 5 No. 2 (Feb 2012) ISSN: 0974- 6846}

fulfillment of the M.Sc. degree in occupational health engineering, Tarbiat Modarres Univ., Tehran,Iran. [in Persian]

2. Ghasemi M (2009) Ergonomics study (Identification, Prediction \& Control) of Human errors in a control room of petrochemical plants using SHERPA, A dissertation thesis for the fulfillment of the M.Sc. degree in Occupational health engineering. Tehran Univ. Medical Sci., Tehran, Iran. [in Persian].

3. ICSO (2004a) Investigation of marine oil and gas' events within recent thirty years. A quarterly J. Health, Safety and environ. Manage. Sys. Iran Continental Shelf Oil Company, summer 2004, No. 8.

4. ICSO (2004b) The accidents of Iran Continental Shelf Oil Company in last 30 years. A quarterly J. Health, Safety and environ. Manage. Sys. Iran Continental Shelf Oil Company, summer 2004, No. 6.

5. Jahangiri $M$ (2005) Human error identification and analysis in Isomax unit of Tehran oil refinery, Using PHEA. A dissertation thesis for the fulfillment of the M.Sc. degree in Occupational Health Engineering. Tehran Univ. Medi. Sci. 2005, Tehran, Iran. [in Persian]

6. Le Bot $P$ (2004) Human reliability data, human error and accident models-illustration through the Three Mile Island accident analysis. Reliability Engg. \& Sys. Safety. 83(2), 153-167.

7. Reason J (1990) Human error. Cambridge Univ. press, NY.

8. RSSB (2005) Rail-specific human reliability assessment technique for driving tasks (T270). Rail Safety \& Standards Board. February.

9. Shorrock ST (2005) Errors of memory in air traffic control. Safety Sci. 43(8), 571-588.

10. Shorrock ST (2007) Errors of perception in air traffic control. Safety Sci. 45(8), 890-904.

11. Shorrock ST (2002) The two-fold path to human error analysis: TRACEr lite retrospection and prediction. Safety Sys. (Newsletter of the Safety-Critical Systems Club), September 2002. 11(3).

12. Shorrock ST and Kirwan B (2002) Development and application of a human error identification tool for air traffic control. Appl. Ergonomics. 33(4), 319-336.

13. Stanton $N$ and Salmon $P$ (2004) Human factors design $\&$ evaluation methods review. Defense Technol. Center, February, 2004.

14. Zarea A (1996) Human errors of operators in cement furnace using HRMS. A dissertation thesis for the fulfillment of the MSc degree in Occupational Health Engineering. Tehran Univ. Medical Sci., Tehran, Iran. [in Persian].

15. Zarei M (2009) The assessment of fire and explosion risk at Isomax unit of Tehran Oil Refinery using DOW F\&E index and the effectiveness of control measures, Thesis submitted for master's degree. Shahid Beheshti Univ. Medical Sci. \& health service-Faculty of Health. [in Persian].

16. Zhang J, Patel VL, Johnson TR and Shortliffe EH (2004) A cognitive taxonomy of medical errors. J. Biomed. Informatics. 37(3), 193-204. 